\title{
A COMPARATIVE STUDY TO ASSESS THE ROLE OF PROPHYLACTIC ANTIBIOTICS IN ELECTIVE LAPAROSCOPIC CHOLECYSTECTOMY
}

\author{
H. C. Srikantaiah 1 , V. R. Anil Kumar², Karthik Aditya ${ }^{3}$, Kiran Kailas $C^{4}$ \\ ${ }^{1}$ Associate Professor, Department of General Surgery, M. S. Ramaiah Medical College and Hospital. \\ ${ }^{2}$ Associate Professor, Department of General Surgery, M. S. Ramaiah Medical College and Hospital. \\ ${ }^{3}$ Assistant Professor, Department of General Surgery, M. S. Ramaiah Medical College and Hospital. \\ ${ }^{4}$ Senior Resident, Department of General Surgery, M. S. Ramaiah Medical College and Hospital.
}

\begin{abstract}
Benign biliary tract diseases are one of the most common surgical problems in the world. Cholelithiasis is rare in the first two decades of life. Incidence gradually increases after 21 years and reaches peak in 5 th and 6th decade women are more commonly affected than men in the ratio of 4:1.1 The advent of laparoscopic surgery ushered in a new era in general surgery in the management of symptomatic gall stones. Open cholecystectomy is associated with a higher wound infection rate ranging from 1-21\%. The use of prophylactic antibiotics reduced this rate to $3 \%-7 \%$ and so has become common practice. Laparoscopic cholecystectomy is associated with smaller wounds and minimal tissue damage and therefore presumably a lower risk of wound infection.
\end{abstract}

\section{METHODOLOGY}

A prospective randomized control study involving a sample size of 52 patients ( 26 in the study group +26 in the control group) was conducted over a period of 2 years. Chi square test of significance was used to test the difference in the proportion between the groups. To test whether there is significant difference in the means of 2 groups; Independent t-test/Mann Whitney test will be used. Statistical analysis was done using IBM SPSS 20 statistical software.

\section{RESULTS}

The mean age in the study group was 43 years and the mean age in the control group was 44.42 . Samples are age matched with $\mathrm{P}=0.421$, Student ' $\mathrm{t}$ ' test. Incidence of Gallbladder disease was more in females in both the study group and the control group. Samples are gender matched with $\mathrm{P}=0.768$. No SSI noted in the control group. 1 patient [3.8\%] had SSI in the study group=1.000, Not significant, Fisher Exact test. E. coli was the organism isolated in the patient with SSI.P=1.000, Not significant, Fisher Exact test. Incidence of bile spillage was $7.7 \%$ in both the control group and the study group=1.000, Not significant, Fisher Exact test.

\section{DISCUSSION}

The use of prophylactic antibiotics in open cholecystectomy to reduce the rate of postoperative infective complications is considered to be the standard of practice. However, its use in laparoscopic cholecystectomy has been an area of conflicting opinion.

\section{CONCLUSION}

In conclusion, the results of this study have shown that avoiding prophylactic antibiotics in patients undergoing elective laparoscopic cholecystectomy increases the incidence of postoperative infective complication but not to a statistically significant degree.

\section{KEYWORDS}

Cholecystectomy, Antibiotic Prophylaxis.

HOW TO CITE THIS ARTICLE: H. C Srikantaiah, V. R Anil Kumar, Karthik Aditya, Kiran Kailas C. "A Comparative Study to Assess the Role of Prophylactic Antibiotics In Elective Laparoscopic Cholecystectomy." Journal of Evolution of Medical and Dental Sciences 2015; Vol. 4, Issue 101, December 17; Page: 16683-16687, DOI: 10.14260/jemds/2015/2492

\section{INTRODUCTION}

Benign biliary tract diseases are one of the most common surgical problems in the world. Gallstones especially affect millions of people worldwide. Cholelithiasis is rare in the first two decades of life. Incidence gradually increases after 21 years and reaches peak in 5 th and 6 th decade women are more commonly affected than men in the ratio of $4: 1 .^{1}$

Financial or Other, Competing Interest: None.

Submission 06-12-2015, Peer Review 07-12-2015,

Acceptance 12-12-2015, Published 17-12-2015.

Corresponding Author:

Dr. Srikantaiah

Deparment of General Surgery,

M. S. Ramaiah Medical College and Hospital,

Bangalore-54.

E-mail: drsrikantaiah@gmail.com

DOI:10.14260/jemds/2015/2492
Female sex, obesity, pregnancy, fatty foods, Crohn's disease, terminal ileal resection, gastric surgery, hereditary spherocytosis, sickle cell disease and thalassemia are associated with an increased risk for developing gall stones. Classic presenting symptoms of the majority of patients include stabbing (Colicky) pain in the right upper quadrant radiating to the back and to the shoulder. Frequently the pain is associated with nausea and vomiting, but is rarely accompanied by jaundice, fever or chills, unless acute cholecystitis. ${ }^{1}$ or cholangitis is present. Once symptomatic, patients tend to have recurring symptoms, usually repeated episodes of biliary colic.

Ultrasound of the abdomen is an extremely useful and accurate method for identifying gallstones and pathologic changes in the gallbladder consistent with acute cholecystitis. Ultrasound of abdomen has a high specificity of $>98 \%$ and sensitivity of $>95 \%$ in diagnosing cholelithiasis. In addition to identifying gallstones, ultrasound can also detail signs of cholecystitis such as thickening of the gallbladder wall, pericholecystic fluid and impacted stone in the neck of the gallbladder. ${ }^{2}$ Dilatation of the extra hepatic $(>10 \mathrm{~mm})$ or 
intrahepatic ( $>4 \mathrm{~mm}$ ) bile ducts suggests biliary obstruction. Surgery plays an important part in the treatment and over half a million cholecystectomies are performed worldwide. During the last 100 years, open cholecystectomy has remained the gold standard for the definitive management of patients with gallstones. The advent of laparoscopic surgery ushered in a new era in general surgery.

One of the main benefits of minimally invasive surgery is the reduced rates of surgical site infection. The advantages of laparoscopic cholecystectomy over open cholecystectomy were earlier return of bowel functions, less postoperative pain, better cosmesis, shorter length of hospital stay, earlier return to full activity and decreased overall cost. Laparoscopic cholecystectomy is now considered the first option and has become the "gold standard" in treating benign gallbladder disease.

The risk of intraoperative injury during laparoscopic cholecystectomy is higher than in open cholecystectomy. It has been anticipated that this will diminish with increasing surgeon experience in the use of laparoscopic procedures. Although both open cholecystectomy and laparoscopic cholecystectomy are well tolerated wound infection remains the most common complication which not only increases the duration of hospital stay, cost of treatment, complications like septicaemia and lastly incisional hernia. Laparoscopic cholecystectomy has the potential to decrease the frequency of infections and also modify their characteristics. The basis of these claims were studies that compared historical controls with patients who underwent laparoscopic cholecystectomies, but these studies were unsatisfactory as they did not take into account advances in improvements in intraoperative and perioperative care of patients.

In the first published study by Barkun et al. they compared mini cholecystectomy with laparoscopic cholecystectomy and showed that patients who underwent laparoscopic cholecystectomy had significantly shorter convalescence and return to normal activities. In the second published study by McMahon et al. they compared open cholecystectomy with laparoscopic cholecystectomy and showed that patients who underwent laparoscopic cholecystectomy had significantly shorter convalescence and return to normal activities. ${ }^{3}$

Open cholecystectomy was associated with a wound infection rate ranging from $1 \%-21 \%$. The use of prophylactic antibiotics reduced this rate to $3 \%-7 \%$ and so has become common practice. Laparoscopic cholecystectomy is associated with smaller wounds and minimal tissue damage and therefore presumably a lower risk of wound infection. Postoperative infection and the need for antibiotic prophylaxis are well documented in open biliary surgery. The use of antibiotic prophylaxis, however, for laparoscopic procedures is unfounded. 4

\section{AIM OF THE STUDY}

a. To assess surgical site infection in patients undergoing elective laparoscopic cholecystectomy.

b. To compare surgical site infection between the two groups.

\section{METHODOLOGY \\ Study Design}

Prospective randomized control study.

\section{Size of the Study Population}

Fifty two (26 in the study group +26 in the control group). Based on a study conducted by Mehmet Uludag et al. on the role of prophylactic antibiotic in elective laparoscopic cholecystectomy, it was observed that mean and standard deviation of length of hospital stay, among the control group was $1.17+/-0.324$ and among the treated group it was found to be $1.5118+/-0.325$ with an alpha error of $5 \%$. Keeping the power of study as $80 \%$, sample size was estimated to be 26 in each arm. The duration of the study was 2 years. Chi square test of significance was used to test the difference in the proportion between the groups. To test whether there is significant difference in the means of 2 groups; independent $t$ test/Mann Whitney test will be used. Statistical analysis was done using IBM SPSS 20 statistical software.

\section{Inclusion Criteria}

1. Diagnosed case of symptomatic cholelithiasis.

2. Patients younger than 60 years.

\section{Exclusion Criteria}

1. Antibiotic intake in the 7 days prior to surgery.

2. Acute cholecystitis in the 6 months prior to surgery.

3. Evidence of cholangitis and/or obstructive jaundice and biliary pancreatitis.

4. Evidence of diabetes mellitus.

5. ASA higher than score 2 .

6. Conversion to open cholecystectomy.

Patients undergoing elective laparoscopic cholecystectomy were selected as suitable for the study protocol. Informed written consent was taken from all the patients participating in the study. Patients were randomly divided into the study group and the control group; 2nd and 3rd generation cephalosporin was administered intravenously during induction of anaesthesia for the patients in the study group. No antibiotic was administered to the control group of patients.

After induction of anaesthesia, skin was disinfected with povidone iodine. Laparoscopic cholecystectomy was performed in all patients. The postoperative course was monitored for and any incidents such as fever, infection of the trocar site or intraabdominal collection of pus, superficial or deep incisional soft tissue surgical site infection. If local signs of inflammation or a pus collection present, bacteriological swabs were taken from the wound site to confirm surgical site infections.

\section{RESULTS}

\begin{tabular}{|c|c|c|c|c|}
\hline \multirow{2}{*}{ Age in Years } & \multicolumn{2}{|c|}{ Study Group } & \multicolumn{2}{c|}{ Control Group } \\
\cline { 2 - 5 } & No & $\%$ & No & $\%$ \\
\hline $31-40$ & 9 & 34.6 & 8 & 30.8 \\
\hline $41-50$ & 14 & 53.8 & 12 & 46.2 \\
\hline $51-60$ & 3 & 11.5 & 6 & 23.1 \\
\hline Total & $\mathbf{2 6}$ & $\mathbf{1 0 0 . 0}$ & $\mathbf{2 6}$ & $\mathbf{1 0 0 . 0}$ \\
\hline Mean \pm SD & \multicolumn{3}{|c|}{$\mathbf{4 3 . 0 0 \pm 5 . 3 6}$} & \multicolumn{4}{|c|}{$\mathbf{4 4 . 4 2 \pm 7 . 1 5}$} \\
\hline
\end{tabular}

The mean age in the study group was 43 years and the mean age in the control group was 44.42. Samples are age matched with $P=0.421$, Student ' $t$ ' test.

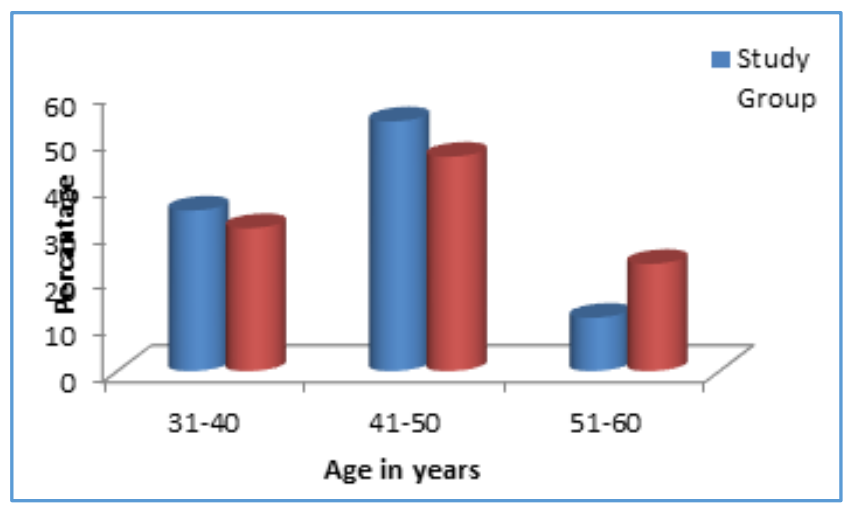

Graph 1: Age distribution of patients studied 


\begin{tabular}{|c|c|c|c|c|}
\hline \multirow{2}{*}{ Gender } & \multicolumn{2}{|c|}{ Study Group } & \multicolumn{2}{c|}{ Control Group } \\
\cline { 2 - 5 } & No & $\mathbf{\%}$ & No & $\mathbf{\%}$ \\
\hline Female & 18 & 69.2 & 17 & 65.4 \\
\hline Male & 8 & 30.8 & 9 & 34.6 \\
\hline Total & $\mathbf{2 6}$ & $\mathbf{1 0 0 . 0}$ & $\mathbf{2 6}$ & $\mathbf{1 0 0 . 0}$ \\
\hline
\end{tabular}

Incidence of gallbladder disease was more in females in both the study group and the control group. Samples are gender matched with $\mathrm{P}=0.768$.

Table 2: Gender distribution of patients studied

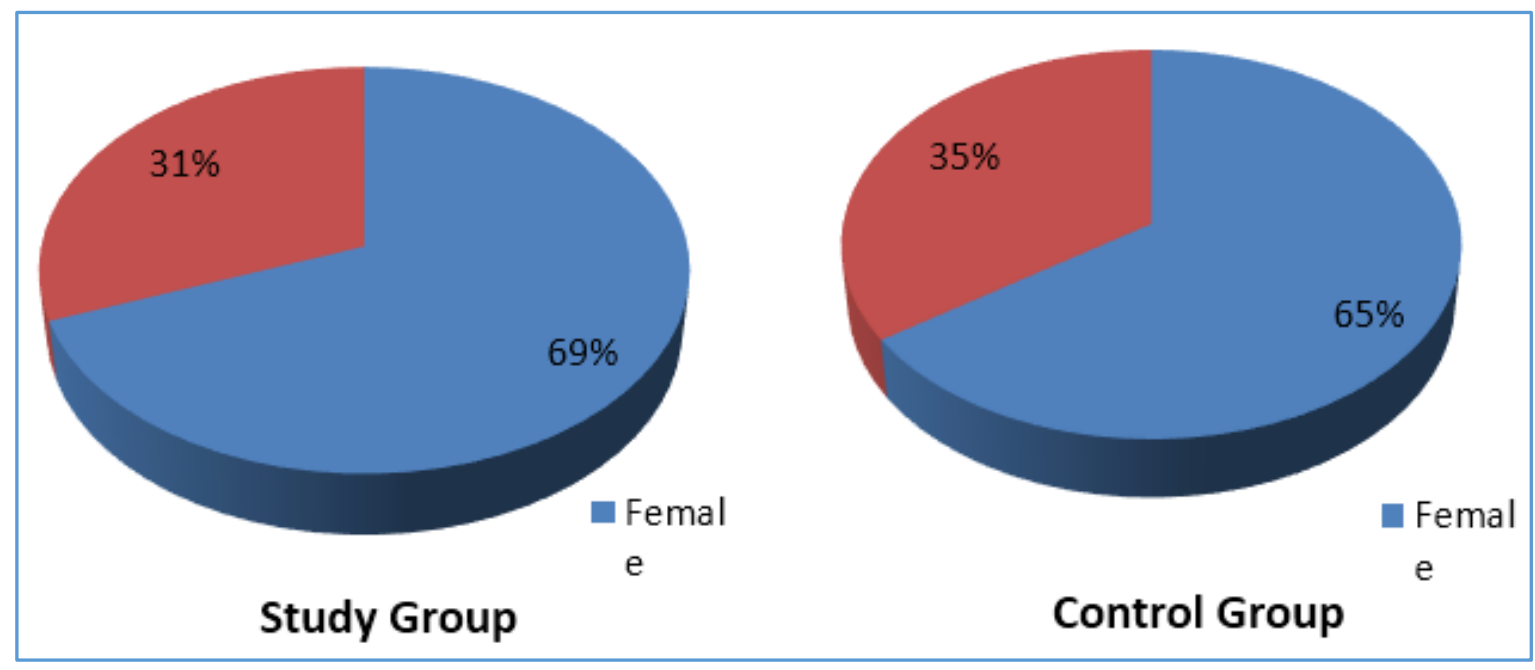

Graph 2: Gender distribution of patients studied

\begin{tabular}{|c|c|c|c|c|}
\hline \multirow{2}{*}{$\begin{array}{c}\text { Antibiotic } \\
\text { Prophylaxis }\end{array}$} & No & $\mathbf{0}$ & No & $\%$ \\
\cline { 2 - 5 } & 26 & 100.0 & 0 & 0.0 \\
\hline No & 0 & 0.0 & 26 & 100.0 \\
\hline Yes & $\mathbf{2 6}$ & $\mathbf{1 0 0 . 0}$ & $\mathbf{2 6}$ & $\mathbf{1 0 0 . 0}$ \\
\hline Total & \multicolumn{2}{|c|}{ Table 3: Antibiotic prophylaxis in two groups of patients studied } \\
\hline
\end{tabular}

Antibiotic prophylaxis [Injection Cefazolin 1g, IV] was given to all the patients in the control group. No antibiotic prophylaxis were given to the patients in study group.

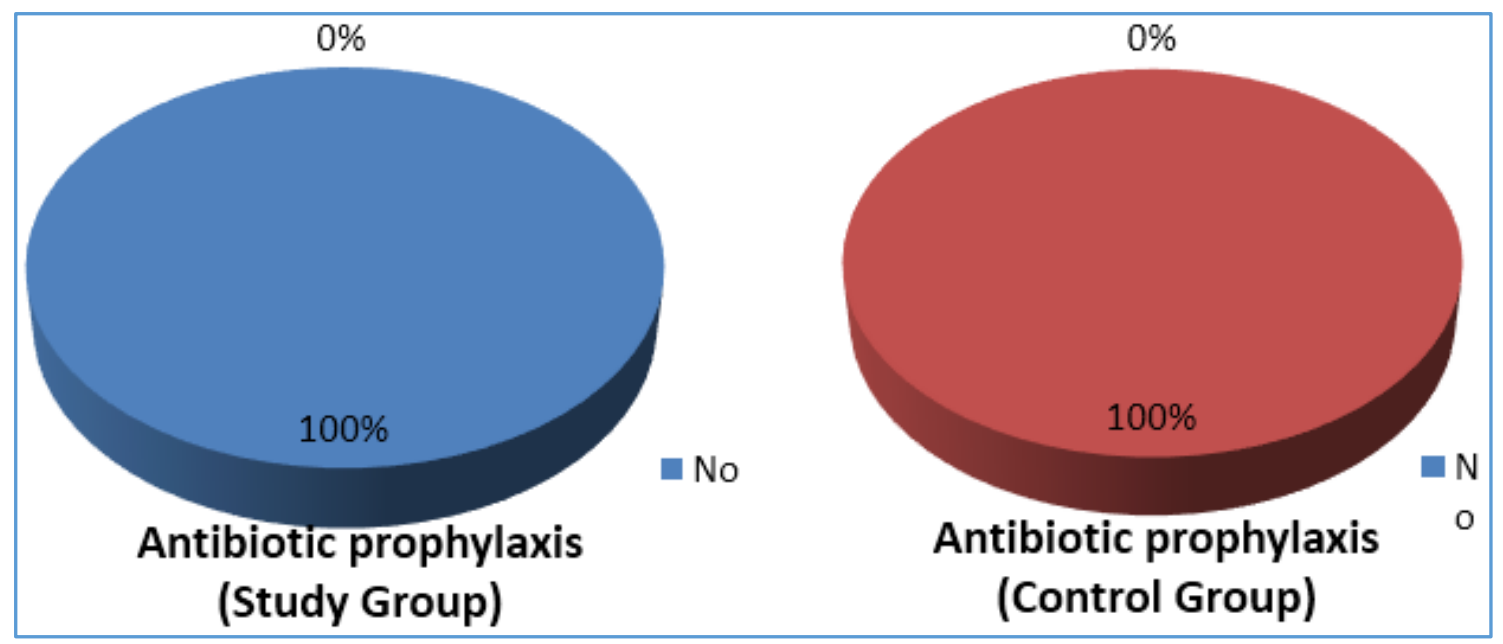

Graph 3: Antibiotic prophylaxis in two groups of patients studied

\begin{tabular}{|c|c|c|c|c|}
\hline \multirow{2}{*}{ SSI } & \multicolumn{2}{|c|}{ Study Group } & No & Control Group \\
\cline { 2 - 5 } & No & $\mathbf{\%}$ & 26 & 100.0 \\
\hline No & 25 & 96.2 & 0 & 0.0 \\
\hline Yes & 1 & 3.8 & $\mathbf{2 6}$ & $\mathbf{1 0 0 . 0}$ \\
\hline Total & $\mathbf{2 6}$ & $\mathbf{1 0 0 . 0}$ & Table 4: SSI in two groups of patients studied \\
\hline \multicolumn{4}{|c|}{}
\end{tabular}


No SSI noted in the control group. One patient [3.8\%] had SSI in the study group=1.000, Not significant, Fisher Exact test.

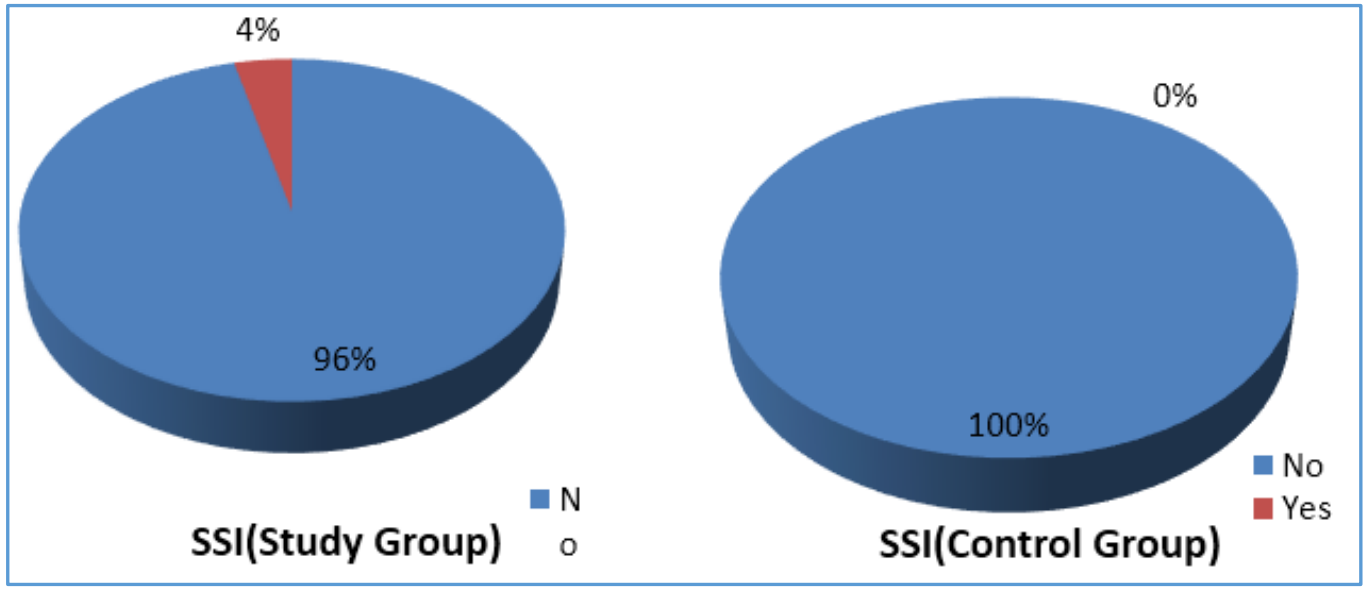

Graph 4: SSI in two groups of patients studied

\begin{tabular}{|c|c|c|c|c|}
\hline \multirow{2}{*}{ Organism } & \multicolumn{2}{|c|}{ Study Group } & No & $\%$ \\
\cline { 2 - 5 } & No & $\mathbf{9}$ & 26 & 100.0 \\
\hline Nil & 25 & 96.2 & 0 & 0.0 \\
\hline E.coli & 1 & 3.8 & $\mathbf{2 6}$ & $\mathbf{1 0 0 . 0}$ \\
\hline Total & $\mathbf{2 6}$ & $\mathbf{1 0 0 . 0}$ & Table 5: Organism isolated in two groups of patients studied \\
\hline \multicolumn{4}{r}{}
\end{tabular}

E.coli was the organism isolated in the patient with SSI. P=1.000, Not significant, Fisher Exact test.

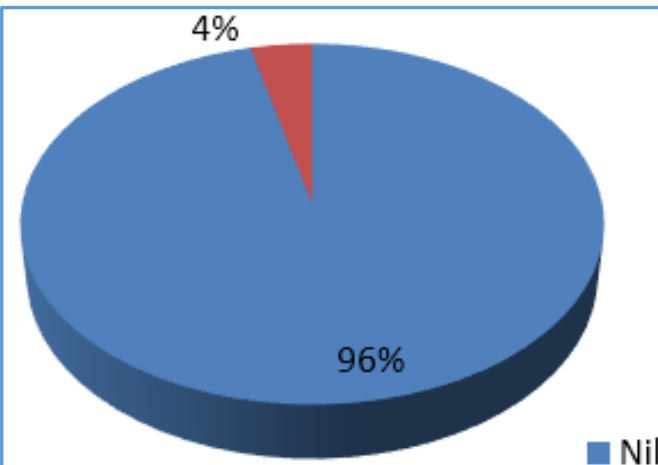

Organism(Study Group)

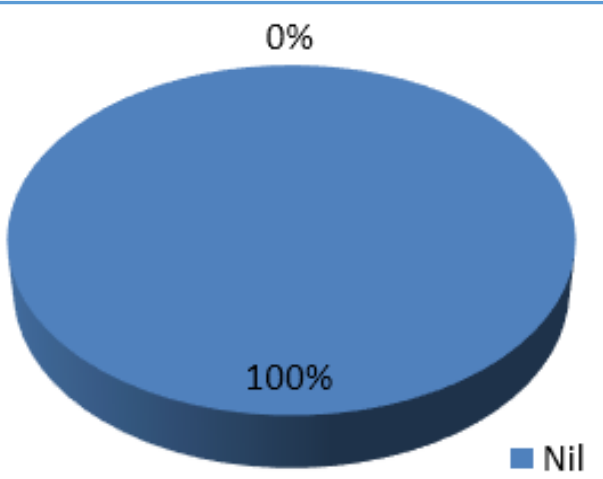

\section{Organism(Control Group)}

Graph 5: Organism isolated in two groups of patients studied

\begin{tabular}{|c|c|c|c|c|}
\hline \multirow{2}{*}{ Bile Spillage } & \multicolumn{3}{|c|}{ Study Group } & \multicolumn{2}{c|}{ Control Group } \\
\cline { 2 - 5 } & No & \% & No & $\%$ \\
\hline No & 24 & 92.3 & 24 & 92.3 \\
\hline Yes & 2 & 7.7 & 2 & 7.7 \\
\hline Total & $\mathbf{2 6}$ & $\mathbf{1 0 0 . 0}$ & $\mathbf{2 6}$ & $\mathbf{1 0 0 . 0}$ \\
\hline \multicolumn{4}{|c}{ Table 6: Bile Spillage in two groups of patients studied } \\
\hline
\end{tabular}

Incidence of bile spillage was $7.7 \%$ in both the control group and the study group=1.000, Not significant, Fisher Exact test. 


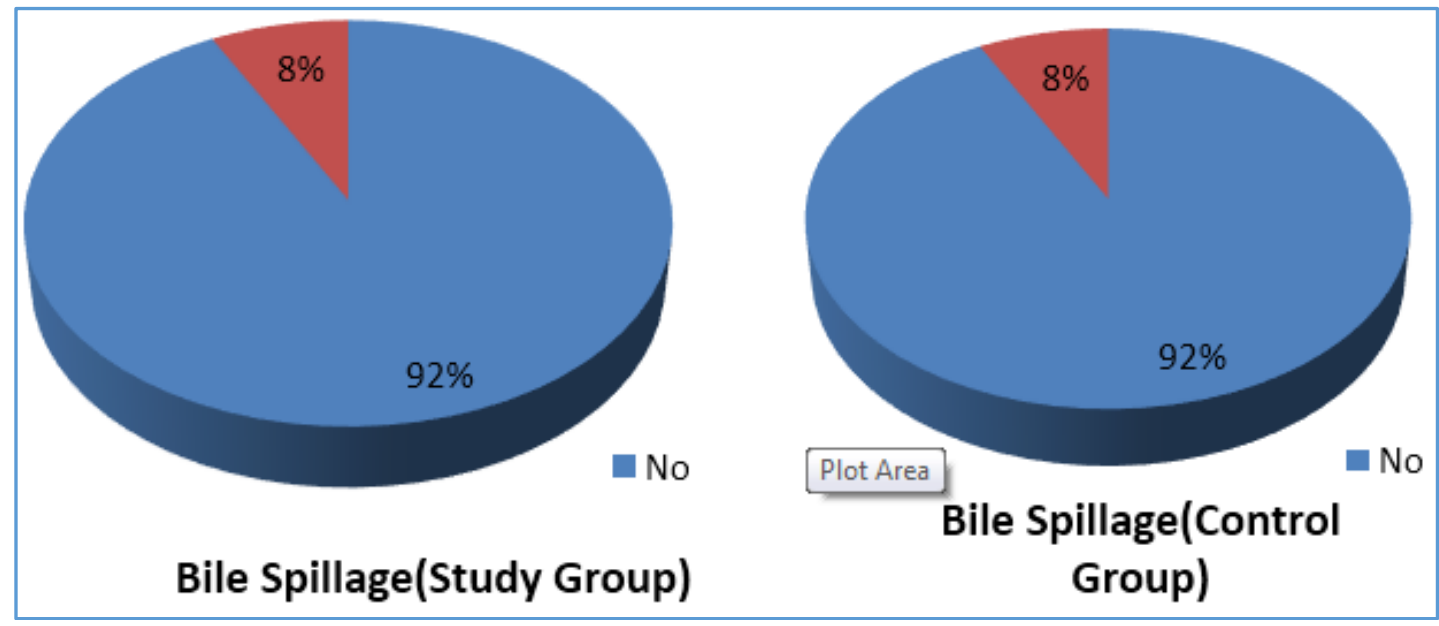

Graph 6: Bile Spillage in two groups of patients studied

\section{DISCUSSION}

The use of prophylactic antibiotics in open cholecystectomy to reduce the rate of postoperative infective complications is considered to be the standard of practice. However, its use in laparoscopic cholecystectomy has been evaluated by many studies with controversial results. Several studies have recommended the use of prophylactic antibiotics stating that it significantly reduces the incidence of postoperative infective complications. On the contrary, several prospective studies have concluded that the use of prophylactic antibiotics in lowrisk patients undergoing laparoscopic cholecystectomy is unnecessary, because the rate of postoperative infective complications is already low in such patients and therefore the use of prophylactic antibiotics will not reduce the rate of postoperative infective complications significantly.

It has been reported in the literature that the average rate of SSI after Laparoscopic Cholecystectomy to be $0.4 \%$ $6.3 \%$, although a higher rate of SSI has been reported after open cholecystectomy. ${ }^{5}$ In this study, the overall postoperative infective complications was $1.9 \%$ (3.8\% in study group and $0.0 \%$ in control group) with no significant statistical difference between the two groups. All infective complications were superficial wound infection and all were treated with pus drainage, wound care and antibiotics. No deep incisional, deep seated or distant infections were reported in this study.

The role of positive bile culture, bile and stones spillage due to intraoperative gallbladder perforation with bile spillage on the occurrence of SSI is still controversial. Intraoperative gallbladder perforation with bile spillage has been reported to occur in $11 \%$ to $20 \%$ laparoscopic cholecystectomies. ${ }^{6}$ In this study bile spillage due to gallbladder perforation occurred in $7.6 \%(n=4)$ of patients. Several studies have stated that intraoperative bile spillage was strongly associated with occurrence of surgical site infections. ${ }^{7,8}$ However, many other studies did not observe this association, concluding that intraoperative gallbladder perforation with bile spillage does not increase the rate of surgical site infections. ${ }^{9}$ In our study as well, no such association was observed.

\section{CONCLUSION}

In conclusion, the results of this study have shown that avoiding prophylactic antibiotics in patients undergoing elective laparoscopic cholecystectomy increases the incidence of postoperative infective complication, but not to a statistically significant degree.

\section{REFERENCES}

1. Thompson Jr JE, Bennion RS, Doty JE, et al.: Predictive factors for bactibilia in acute cholecystitis. Arch Surg 1990;125:261-264.

2. Bellows CF, Berger DH, Crass RA: Management of gallstones. Am Fam Physician 2005;72:637-642.

3. Mangram AJ, Horan TC, Pearson ML, et al. Guideline for prevention of surgical site infection, 1999. Centres for Disease Control and Prevention (CDC) Hospital Infection Control Practices Advisory Committee. Am J Infect Control? 1999;27:97-132.

4. Wittman DH, Condon RE. Prophylaxis of postoperative infections. Infection. 1991;19(Suppl 6):S337-344.

5. Nichols RL. Preventing surgical site infections. Clin Med Res. 2004;2:115-118.

6. 11. Den Hoed PT, Boelhouwer RU, Veen HF, et al. Infections and bacteriological data after laparoscopic and open gallbladder surgery. J Hosp Infect 1998;39:27-37.

7. 12. Chuang SC, Lee KT, Chang WT, et al. Risk factors for wound infection after cholecystectomy. J Formos Med Assoc 2004;103:607-612.

8. 13. Chang WT, Lee KT, Chuang SC, et al. The impact of prophylactic antibiotics on postoperative infection complication in elective laparoscopic cholecystectomy: a prospective randomized study. Am J Surg 2006;191:721-725.

9. 14. Koc M, Zulfikaroğlu B, Kece C, et al. A prospective randomized study of prophylactic antibiotics in elective laparoscopic cholecystectomy. Surg Endosc 2003;17:1716-1718.

10. Mahatharadol V. A re-evaluation of antibiotic prophylaxis in laparoscopic cholecystectomy: a randomized controlled trial.

J Med Assoc Thai 2001;84:105-108. 